\title{
Epidemiology and outcome of invasive pneumococcal disease among adults in Belgium, 2009-2011
}

J Verhaegen (jan.verhaegen@uzleuven.be) ${ }^{1}$, J Flamaing², W De Backer ${ }^{3}$, B Delaere ${ }^{4}, K_{\text {Kan Herck5,6, F Surmont }}^{7}$, Y Van Laethem ${ }^{8}$,

P Van Damme ${ }^{5}$, W Peetermans 9

1. Department of Microbiology, University Hospitals Leuven, KU Leuven, Belgium

2. Department of Geriatric Medicine, University Hospitals Leuven, KU Leuven, Belgium

3. Department of Respiratory Medicine, University Hospital Antwerp, Antwerp, Belgium

4. Infectious Diseases Department, Cliniques Universitaires UCL de Mont- Godinne, Yvoir, Belgium

5. Vaccine \& Infectious Disease Institute, University of Antwerp, Antwerp, Belgium

6. Department of Public Health, Ghent University, Ghent, Belgium

7. Medical Department, Specialty Care Business Unit Pfizer, Brussels, Belgium

8. Department of Infectious Diseases, St Pierre Hospital, Brussels, Belgium

9. Department of Internal Medicine and Infectious Diseases, University Hospitals Leuven, KU Leuven, Belgium

Citation style for this article:

Verhaegen J, Flamaing J, De Backer W, Delaere B, Van Herck K, Surmont F, Van Laethem Y, Van Damme P, Peetermans W. Epidemiology and outcome of invasive pneumococcal disease among adults in Belgium, 2009-2011. Euro Surveill. 2014;19(31):pii=20869. Available online: http://www.eurosurveillance.org/ ViewArticle.aspx?Articleld $=20869$

Article submitted on 19 August 2013 / published on 07 August 2014

This epidemiological study examined morbidity and case fatality of invasive pneumococcal disease (IPD) in adults in Belgium as well as distribution and antibiotic susceptibility of Streptococcus pneumoniae serotypes. Adults hospitalised with microbiologically proven IPD were prospectively enrolled. The study started in 2009 with patients aged $\geq 50$ years, whereas in 2010 and 2011 , patients aged $\geq 18$ years were included. The clinical presentation, patient profile, treatment, outcome, and mortality were recorded during hospitalisation. Outcome was also assessed one month after discharge. Of the 1,875 patients with IPD identified, 1,332 were included in the analysis. Bacteraemic pneumonia, affecting 1,049 of the patients, was the most frequent IPD type (79\%), and chronic obstructive pulmonary disease and cancer were the main comorbidities. One-third of patients required admission to intensive care unit. A total of 208 (16\%) patients died during hospitalisation and an additional 21 (2\%) within one month after discharge. Case fatality rates of $\geq 20 \%$ were observed in patients with chronic heart failure, hepatic disease, and renal insufficiency. Serotypes $7 \mathrm{~F}, 1,19 \mathrm{~A}$, and 3 were the most prevalent and together accounted for $47 \%(569 / 1,214)$ of all IPD cases and $42 \%(80 / 189)$ of mortality. Of the patient isolates, $21 \%$ $(255 / 1,204)$ were resistant to erythromycin and $22 \%$ $(264 / 1,204)$ to tetracycline. Penicillin non-susceptibility was mostly found in serotype $19 \mathrm{~A}$ isolates. These baseline data are essential when assessing the impact of pneumococcal conjugate vaccination in adults in the future.

\section{Introduction}

In industrialised countries, the risk of invasive pneumococcal disease (IPD) remains high among older adults despite the availability of the 23-valent pneumococcal polysaccharide vaccine (PPV23) since 1983 [1]. In a large number of these countries, including Belgium,
PPV23 is recommended since 1985 for all adults $\geq 65$ years of age and for persons between two and 64 years-old at high risk for pneumococcal infections due to living conditions or underlying medical conditions including asplenia, human immunodeficiency virus (HIV) infection, immunodeficiency or chronic cardiac, pulmonary, renal or hepatic diseases as from 50 years of age $[2,3]$. In 2004 , the 7 -valent pneumococcal conjugate vaccine $\left(P \mathrm{PV}_{7}\right)$ for infant vaccination became available in Belgium in a $3+1$ schedule at full charge of the parents and, in $2007, \mathrm{PCV}_{7}$ was added free of charge to the universal infant vaccination programme in a 2+1 schedule at two, four and 12 months of age. Since September 2011, $\mathrm{PCV}_{7}$ has been replaced by the 13-valent pneumococcal conjugate vaccine (PCV13) in the Belgian childhood vaccination schedule. In 2011, PCV13 was also approved by the European Medicines Agency for the prevention of IPD in adults $\geq 50$ years of age [4]. The Belgian recommendations regarding pneumococcal vaccination in adults were updated in July 2013 to also include PCV13 [2], however, there is no publicly funded pneumococcal vaccination programme for adults in Belgium.

A national IPD surveillance programme has existed in Belgium since 1986. It monitors the number of cases for all ages, type of IPD, serotypes or serogroups, and antibiotic susceptibility, but only few clinical data [5]. An active IPD surveillance network for young children started in Belgium in 2002 [6,7]. It showed that, two years after implementation of $\mathrm{PCV}_{7}$ in children $<2$ years of age, the incidence of vaccine-serotype IPD declined by $96 \%$ in this population but that the incidence of non-vaccine-serotype IPD increased two to three-fold [6]. Because the clinical data to assess the burden of disease in adults were lacking, a prospective, active, hospital-based study was started in 2009 to analyse the morbidity and case fatality rate of IPD in adults 
aged $\geq 18$ and $\geq 50$ years, the distribution of pneumococcal serotypes and their antibiotic susceptibility, and the factors affecting disease outcome. We report the results for three years (2009-2011) of this study to document the epidemiology and the burden of IPD before the introduction of PCV13.

\section{Methods}

\section{Study design}

This is a prospective, active, hospital-based epidemiological study of IPD in adults in Belgium. Fifty hospitals participated, corresponding to $44 \%$ of the acute care hospitals in Belgium. Three of these hospitals provided data for only the first year of the study, five during two years, and 42 during the three-year study period.

Adults hospitalised with microbiologically confirmed IPD (defined as isolation of Streptococcus pneumoniae from a normally sterile body site such as blood or cerebrospinal fluid) were eligible for inclusion. During the first year of study (2009), only adults aged $\geq 50$ years were included, but as of 2010, the study was extended to all adults aged $\geq 18$ years. The patient or a legal representative gave an informed consent for inclusion. If no informed consent was obtained, the patient was considered as a screen failure and clinical data were excluded from the analysis. The study was approved by the institutional review boards and local ethics committees of the participating hospitals.

General baseline information was collected at inclusion, including detailed demographics, type of IPD, laboratory data, relevant medical history, and previous vaccination against $S$. pneumoniae and seasonal influenza. The clinical presentation, complications, diagnostic procedures, and treatment were documented by the treating physician during hospital stay. The disease outcome and persisting symptoms and signs were documented at discharge and one month after discharge. All patients were managed according to the hospital's standard protocol for IPD.

\section{Microbiology}

Pneumococcal culture was carried out by the clinical microbiology laboratory of each hospital using routine techniques. Pneumococcal isolates inoculated on blood agar plates or tubes were sent to the Belgian National Reference Laboratory for Pneumococci (University of Leuven, Belgium) for capsular typing and antibiotic susceptibility testing.

Serotyping of pneumococcal isolates was done by phase-contrast microscopy using the Quellung reaction with serotype/serogroup-specific sera obtained from the Statens Serum Institute (Copenhagen, Denmark). Antibiotic susceptibility was assessed using the disk diffusion method on Mueller Hinton blood agar plates: penicillin (oxacillin, $1 \mu \mathrm{g}$ ), erythromycin $(15 \mu \mathrm{g})$, tetracycline $(30 \mu \mathrm{g})$, and ofloxacin $(5 \mu \mathrm{g})$. Isolates were categorised as fully susceptible, intermediately resistant, or resistant according to the interpretive standards (document M100-S22) of the Clinical and Laboratory Standards Institute (Wayne, PA) [8].

For isolates with oxacillin zone diameters $\leq 19 \mathrm{~mm}$, penicillin minimum inhibitory concentrations (MICs) were determined with Epsilometer (E)-test on Mueller Hinton blood agar plates. For the interpretation of penicillin MIC results, criteria for parenteral penicillin (non-meningitis) were used.

\section{Statistical analysis}

Calculations and statistical analyses were performed with SAS (version 9.3 for Windows) statistical package (SAS Institute, Cary, NC). Quantitative variables were expressed as means and standard deviations (SD) or as medians and interquartile ranges (IQR). Categorical findings were summarised in frequency tables. Mean values were compared by one way analysis of variance, whereas proportions were compared using the chi-squared or Fisher's exact test. The association between outcome at discharge and covariates (age, IPD type, comorbidities, and vaccination status) was assessed by univariate and multivariate ordinal logistic regression and was expressed as an odds ratio with a $95 \%$ confidence interval $(95 \% \mathrm{Cl})$. In general, 'age' was preferred to age categories. A two-tailed p-value $<0.05$ was considered statistically significant.

\section{Results}

\section{Participants}

A total of 1,875 patients hospitalised with IPD were eligible. Informed consent was not obtained for 467 patients and, therefore, clinical data from these patients were excluded from analysis. In most cases, the informed consent was not obtained because of the patient's poor physical condition or because the patient was discharged before microbiological confirmation of IPD. Average age and sex ratio of these patients were similar to the analysed population (data not shown).

To avoid inclusion of nosocomial IPD cases, 76 IPD cases were also excluded because the interval between hospitalisation and blood draw was $\geq 5$ days. Thus, 1,332 patients were included in the analysis, with only 220 of them being between 18 and 49 years of age partly because patients in this age group were only included during the last two years of the study. A total of 208 patients died during hospitalisation. Of the 1,124 patients who were discharged from hospital, 141 $(13 \%)$ were lost to follow-up so that one-month followup results were analysed in 983 patients.

Of the total 1,332 patients included in the analysis $52 \%$ were male and the mean age was 66 years (range: 18-98). Three age groups comprising 18 to 49 yearolds, 50 to 64 year-olds and those aged $\geq 65$ years were considered for the study, however in some analyses patients aged $\geq 50$ years were compared to those aged 18 to 49 years. Baseline characteristics for the three age 
TABLE 1

Baseline characteristics of patients with invasive pneumococcal disease by age group, Belgium, 2009-2011 (n=1,332)

\begin{tabular}{|c|c|c|c|c|}
\hline \multirow{2}{*}{ Characteristics } & \multicolumn{3}{|c|}{ Age group, n (\%) } & \multirow{2}{*}{$P$ value } \\
\hline & $18-49$ years $(n=220)$ & $50-64$ years $(n=370)$ & $\geq 65$ years $(n=742)$ & \\
\hline \multicolumn{5}{|l|}{ Sex } \\
\hline Female & $110(50)$ & $176(48)$ & $348(47)$ & \multirow{2}{*}{0.72} \\
\hline Male & $110(50)$ & $194(52)$ & $394(53)$ & \\
\hline \multicolumn{5}{|l|}{ Living condition } \\
\hline At home & 218 (99) & $361(98)$ & $621(84)$ & \multirow{3}{*}{$<0.0001$} \\
\hline In nursing home or other care centre & $1(11)$ & $7(2)$ & $116(16)$ & \\
\hline Unknown & $1((1)$ & $2(41)$ & $5(41)$ & \\
\hline \multicolumn{5}{|l|}{ Comorbidities $^{\mathrm{a}}$} \\
\hline Any & $118(54)$ & $274(74)$ & $627(85)$ & $<0.0001$ \\
\hline Chronic obstructive pulmonary disease & $15(7)$ & $89(24)$ & $231(31)$ & $<0.0001$ \\
\hline Cancer & $13(6)$ & $81(22)$ & $203(27)$ & $<0.0001$ \\
\hline Heart failure & $3(1)$ & $40(11)$ & $206(28)$ & $<0.0001$ \\
\hline Diabetes & $11(5)$ & $47(13)$ & $146(20)$ & $<0.0001$ \\
\hline Renal insufficiency & $3(1)$ & $32(9)$ & 144 (19) & $<0.0001$ \\
\hline Immunosuppression & $21(10)$ & $51(14)$ & $100(14)$ & 0.32 \\
\hline$\geq 2$ comorbidities per patient & $50(23)$ & $154(42)$ & $399(54)$ & $<0.0001$ \\
\hline \multicolumn{5}{|c|}{ Previous vaccination against Streptococcus pneumoniae } \\
\hline Yes & $10(5)$ & $20(5)$ & $62(8)$ & \multirow{3}{*}{0.0023} \\
\hline No & $179(81)$ & $242(65)$ & $401(54)$ & \\
\hline Unknown & $31(14)$ & $108(29)$ & $279(38)$ & \\
\hline \multicolumn{5}{|l|}{ Previous vaccination against influenza } \\
\hline Yes & $18(8)$ & $79(21)$ & $326(44)$ & \multirow{3}{*}{$<0.0001$} \\
\hline No & $181(82)$ & $230(62)$ & $278(38)$ & \\
\hline Unknown & $21(10)$ & $61(17)$ & $138(19)$ & \\
\hline \multicolumn{5}{|c|}{ Oral antibiotics within 24 hours before admission } \\
\hline Yes & $14(6)$ & $15(4)$ & $37(5)$ & \multirow{3}{*}{0.46} \\
\hline No & $206(94)$ & $354(96)$ & $705(95)$ & \\
\hline Unknown & o (o) & $1(\ll 1)$ & $\mathrm{o}(0)$ & \\
\hline
\end{tabular}

${ }^{a}$ Only comorbidities found in more than $10 \%$ of the patients are shown.

groups are described in Table 1. The number of cases increased with age and the majority were $\geq 65$ yearsold. Comparing the number of cases per year per age group (110 in the 18-49 years, 121 in the 50-64 years and 237 in the $\geq 65$ years) with the size of the population in Belgium per age group at the time of the study (4.6 million 18-49 year-olds, 2 million 50-64 year-olds and 1.8 million $\geq 65$ year-olds), there appeared to be almost three times more cases in the 50 to 64 years age group compared to the 18 to 49 years, and almost six times more cases in the $\geq 65$ year-olds.

Most patients had at least one chronic comorbidity, and the proportion increased from 54\% (118/220) in patients aged between 18 and 49 years to $85 \%$ $(627 / 742)$ in patients aged $\geq 65$ years. Furthermore, $45 \%$ $(603 / 1,326)$ of patients had $\geq 2$ predisposing comorbidities. Chronic obstructive pulmonary disease and cancer were the most frequent comorbidities in the two older age groups. Even though the vast majority of patients had a comorbidity or were at an age where pneumococcal vaccination is recommended, less than $10 \%$ (92/1,332) were vaccinated with PPV23. Vaccination against seasonal influenza increased with increasing age, from $8 \%(18 / 220)$ in patients aged between 18 and 49 years to $44 \%(326 / 742)$ in patients aged $\geq 65$ years. Nearly $5 \%(66 / 1,332)$ of patients took oral antibiotics within 24 hours before hospitalisation.

\section{Type and outcome of invasive pneumococcal disease}

Of the 1,332 patients, 1,049 (79\%) had bacteraemic pneumonia (Table 2). Patients aged between 18 and 49 years were hospitalised for a median duration of 7.5 days (IQR: 5-13) compared to 12 days (IQR: 7-22) for patients aged $\geq 50$ years. Admission to an intensive care unit (ICU) was more frequent in older patients $(42 \%$ $(154 / 370)$ in $50-64$ year-olds vs. $25 \%(54 / 219)$ in $18-49$ 
Distribution of invasive pneumococcal disease types by patient age, Belgium, 2009-2011 ( $\mathrm{n}=1,332)$

\begin{tabular}{|c|c|c|c|c|}
\hline \multirow[b]{2}{*}{ Type of IPD } & \multirow[b]{2}{*}{ Total $(n=1,332)$} & \multicolumn{3}{|c|}{ Age group, $n(\%)$} \\
\hline & & $\begin{array}{c}18-49 \text { years } \\
(n=220)\end{array}$ & $\begin{array}{c}50-64 \text { years } \\
(\mathrm{n}=370)\end{array}$ & $\begin{array}{c}\geq 65 \text { years } \\
(n=742)\end{array}$ \\
\hline Bacteraemic pneumonia & $1,049(79)$ & $170(77)$ & $276(75)$ & $603(81)$ \\
\hline Empyema & $94(7)$ & $21(10)$ & $32(9)$ & $41(6)$ \\
\hline Meningitis & $73(6)$ & $8(4)$ & $32(9)$ & $33(4)$ \\
\hline Bacteraemia without focus ${ }^{a}$ & $73(6)$ & $8(4)$ & $17(5)$ & $48(7)$ \\
\hline Other (e.g. septic arthritis, endocarditis, or peritonitis) & $43(3)$ & $13(6)$ & $13(4)$ & $17(2)$ \\
\hline
\end{tabular}

IPD: invasive pneumococcal disease.

a Streptococcus pneumoniae isolated from blood culture without localised infection identified.

\section{TABLE 3}

Admission to intensive care unit and disease outcome at discharge by age and type of invasive pneumococcal disease, Belgium, 2009-2011 ( $\mathrm{n}=1,329)^{\mathrm{a}}$

\begin{tabular}{|c|c|c|c|c|c|c|c|}
\hline \multirow[b]{2}{*}{ Category } & \multirow[b]{2}{*}{$\mathrm{n}$} & \multirow[b]{2}{*}{$\begin{array}{c}\text { Admission } \\
\text { to ICU } \\
\text { n (\%) }\end{array}$} & \multicolumn{3}{|c|}{ Outcome at discharge } & \multicolumn{2}{|c|}{ Univariate OLR } \\
\hline & & & $\begin{array}{l}\text { Cured } \\
\text { n (\%) }\end{array}$ & $\begin{array}{c}\text { Discharged } \\
\text { with } \\
\text { persisting } \\
\text { symptoms } \\
n(\%)\end{array}$ & $\begin{array}{l}\text { Death } \\
\text { n (\%) }\end{array}$ & $\begin{array}{l}\text { Odds ratio }(95 \% \\
\text { CI) }\end{array}$ & $\begin{array}{l}\text { Overall } \\
\mathrm{p} \text { value }\end{array}$ \\
\hline Total $^{a}$ & 1,329 & $434(33)$ & $884(67)$ & $237(18)$ & $208(16)$ & - & - \\
\hline \multicolumn{8}{|l|}{ Age in years } \\
\hline $18-49$ & 219 & $54(25)$ & $157(72)$ & $49(22)$ & $13(6)$ & 1 & \multirow{3}{*}{0.044} \\
\hline $50-64$ & 370 & $154(42)$ & $240(65)$ & $83(22)$ & $47(13)$ & $1.42(0.98-2.04)$ & \\
\hline$\geq 65$ & 740 & $226(31)$ & $487(66)$ & $105(14)$ & $148(20)$ & $1.52(1.10-2.12)$ & \\
\hline \multicolumn{8}{|c|}{ Type of invasive pneumococcal disease } \\
\hline Bacteraemic pneumonia & 1,049 & $303(29)$ & $722(69)$ & $169(16)$ & $155(15)$ & 1 & \multirow{5}{*}{0.0049} \\
\hline Empyema & 94 & $49(52)$ & $49(52)$ & $35(37)$ & $10(11)$ & $1.61(1.07-2.45)$ & \\
\hline Meningitis & 73 & $59(81)$ & $38(52)$ & $16(22)$ & $19(26)$ & $2.06(1.31-3.25)$ & \\
\hline Bacteraemia without focus & 73 & $12(16)$ & $51(70)$ & $4(6)$ & $18(25)$ & $1.12(0.69-1.84)$ & \\
\hline $\begin{array}{l}\text { Other (e.g. septic arthritis, } \\
\text { endocarditis, or peritonitis) }\end{array}$ & 43 & $11(26)$ & $24(56)$ & $13(30)$ & $6(14)$ & $1.53(0.84-2.79)$ & \\
\hline
\end{tabular}

$\mathrm{CI}$ : confidence interval; ICU: intensive care unit; OLR: ordinal logistic regression; SD: standard deviation.

${ }^{a}$ Data missing for three patients.

year-olds; $p=0.001)$ and for patients with meningitis (81\% (59/73); $p=0.0001$ ) (Table 3). Only $16 \%(12 / 73)$ of patients with bacteraemia without focus were admitted to ICU. Depending on the age group, the median durations of stay in an ICU varied from four to six days (IQR: 2-15), with four days for the 18 to 49 year-olds, six days for the 50 to 64 year-olds and five days for those aged $\geq 65$ years, The median durations of hospitalisation after discharge from ICU were seven to 10.5 days (IQR: 0-21), with seven days for the 18 to 49 year-olds, nine days for the 50 to 64 year-olds and 10.5 for those 65 years-old and over. The median duration of ICU stay was significantly higher for deceased patients ( 9 vs. 5 days, $p=0.0009$ ).

For empirical treatment before the microbiological results became available, the three most used antibiotics on patients with available data $(n=1,327)$ were amoxicillin-clavulanic acid intravenous (in 615 (46\%) patients), third-generation cephalosporin (in 116 (9\%) patients), and fluoroquinolones (in 71 (5\%) patients). Also, 65 (5\%) patients received a combination of amoxicillin-clavulanic acid and macrolides. After microbiological diagnosis, antibiotic treatment was changed to amoxicillin in 142 patients and penicillin in 151 patients. Overall, the antibiotic treatment was adapted in $55 \%$ $(723 / 1,327)$ of patients after the microbiological results became available. The majority of the 73 patients with meningitis were treated with third-generation cephalosporin (51 patients) or penicillin (16 patients).

During hospitalisation $16 \%(208 / 1,329)$ of patients died. Duration of hospitalisation was significantly lower in deceased patients (median, 9 vs. 11 days; $\mathrm{p}=0.0013)$.

Of the 1,329 patients with outcome data at discharge, $884(67 \%)$ were cured and $237(18 \%)$ had persisting 
symptoms and signs, including 18 with persistent fatigue (8\%), 16 with pleural pain (7\%), 49 with dyspnoea (21\%), and 86 with pleural infiltrate (36\%). Persisting symptoms and signs were less common in patients with bacteraemia without focus than in patients with other types of IPD, and patients with empyema had the highest rate of persisting symptoms and signs. Of the 983 patients with available onemonth follow-up data, an additional 21 (2\%) patients died within one month of discharge, 749 (76\%) patients were cured, and 213 (22\%) still had persisting symptoms and signs. The case fatality rate at discharge was highest for meningitis, lowest for empyema, and increased with increasing age (from 6\% (13/219) in patients aged $18-49$ years to $20 \%(148 / 740)$ in those aged $\geq 65$ years; $p<0.0001$ ). The case fatality rate for meningitis decreased with increasing age (from $37 \%$ $(3 / 8)$ in patients aged $18-49$ years to $18 \%(6 / 33)$ in patients aged $\geq 65$ years), whereas the case fatality rate of bacteraemia without focus increased (from $0 \%(0 / 8)$ in patients aged $18-49$ years to $31 \%(15 / 48)$ in patients aged $\geq 65$ years). A case fatality rate higher than $20 \%$ was seen for patients with comorbidities such as asplenia, alcoholism, renal insufficiency, hepatic disease, or heart failure (Table 4). Multivariate logistic regression showed that the risk of death was higher for patients with heart failure, renal insufficiency, and alcoholism but not for patients with chronic obstructive pulmonary disease, immunosuppression, or cancer. For patients admitted to ICU, case fatality rate was $22 \%(12 / 54)$ in patients aged $<50$ years and $32 \%(122 / 380)$ in patients aged $\geq 50$ years.

\section{Pneumococcal serotype distribution and antibiotic susceptibility}

Of the 1,214 serotypes identified in isolates, serotypes 7F (159 isolates (13\%)) serotypes 1 (154 isolates (13\%)), serotypes 19A (145 isolates (12\%)), and serotypes 3 (111 isolates ( $9 \%)$ ) accounted for nearly half of IPD cases in adults (Figure 1). Serotype 1 was more prevalent in patients aged between 18 and 49 years (27\% (54/200), p 10.0001$)$, whereas serotype 3 was more prevalent in those aged $\geq 65$ years (13\% (84/669), p<0.0001). Serotype $7 \mathrm{~F}$ was the most prevalent in patients with

TABLE 4

Disease outcome at discharge for patients with invasive pneumococcal disease, by comorbidity, Belgium, 2009-2011 $(\mathrm{n}=1,329)^{\mathrm{a}}$

\begin{tabular}{|c|c|c|c|c|c|c|c|c|}
\hline \multirow[b]{2}{*}{ Category } & \multirow[b]{2}{*}{$n$} & \multicolumn{3}{|c|}{ Outcome at discharge } & \multicolumn{2}{|c|}{ Univariate OLR } & \multicolumn{2}{|c|}{ Multivariate OLR } \\
\hline & & $\begin{array}{l}\text { Cured } \\
\mathrm{n}(\%)\end{array}$ & $\begin{array}{l}\text { Discharged } \\
\text { with } \\
\text { persisting } \\
\text { symptoms } \\
n(\%)\end{array}$ & $\begin{array}{l}\text { Death } \\
n(\%)\end{array}$ & $\begin{array}{l}\text { Odds ratio } \\
(95 \% \mathrm{Cl})\end{array}$ & P value & $\begin{array}{l}\text { Odds ratio } \\
(95 \% \mathrm{Cl})\end{array}$ & P value \\
\hline Total $^{\mathrm{a}}$ & 1,329 & $884(67)$ & $237(18)$ & $208(16)$ & - & - & - & - \\
\hline \multicolumn{9}{|l|}{ Comorbidity } \\
\hline No & 313 & $217(69)$ & $67(21)$ & $29(9)$ & 1 & - & - & - \\
\hline Any & 1,016 & $667(66)$ & $170(17)$ & $179(18)$ & $1.29(0.98-1.69)$ & 0.067 & $1.20(0.91-1.60)$ & 0.20 \\
\hline Number of comorbidities, mean \pm SD & 1,323 & $1.43 \pm 1.19$ & $1.4 \pm 1.22$ & $1.88 \pm 1.28$ & $1.18(1.08-1.29)$ & 0.0004 & - & - \\
\hline COPD & 335 & $226(68)$ & $56(17)$ & $53(16)$ & $0.97(0.75-1.26)$ & 0.83 & $0.90(0.69-1.19)$ & 0.47 \\
\hline Asthma & 68 & $47(69)$ & $12(18)$ & $9(13)$ & $0.88(0.52-1.48)$ & 0.63 & $0.88(0.51-1.51)$ & 0.65 \\
\hline Heart failure & 249 & $141(57)$ & $44(18)$ & $64(26)$ & $1.85(1.41-2.43)$ & $<0.0001$ & $1.70(1.26-2.30)$ & 0.0006 \\
\hline Renal insufficiency & 179 & $103(58)$ & $25(14)$ & $51(29)$ & $1.82(1.34-2.48)$ & 0.0001 & $1.63(1.16-2.29)$ & 0.0047 \\
\hline Hepatic disease & 104 & $62(60)$ & $15(14)$ & $27(26)$ & $1.56(1.05-2.31)$ & 0.027 & $1.38(0.91-2.10)$ & 0.13 \\
\hline Immunosuppression & 172 & $116(67)$ & $28(16)$ & $28(16)$ & $0.99(0.71-1.38)$ & 0.93 & $0.96(0.67-1.39)$ & 0.84 \\
\hline HIV infection & 24 & $18(75)$ & $3(13)$ & $3(13)$ & $0.68(0.27-1.70)$ & 0.41 & $0.96(0.37-2.50)$ & 0.93 \\
\hline Cancer & 296 & $192(65)$ & $48(16)$ & $56(19)$ & $1.17(0.90-1.52)$ & 0.26 & $1.16(0.87-1.54)$ & 0.31 \\
\hline Diabetes & 203 & $136(67)$ & $37(18)$ & $30(15)$ & $0.98(0.72-1.34)$ & 0.91 & $0.83(0.59-1.15)$ & 0.26 \\
\hline Asplenia & 11 & $6(55)$ & $1(9)$ & $4(36)$ & $2.15(0.70-6.55)$ & 0.18 & $2.18(0.69-6.87)$ & 0.18 \\
\hline Alcoholism & 59 & $28(48)$ & $13(22)$ & $18(31)$ & $2.37(1.45-3.86)$ & 0.0006 & $2.79(1.65-4.73)$ & 0.0001 \\
\hline Hypertension & 78 & $54(69)$ & $12(15)$ & $12(15)$ & $0.89(0.55-1.45)$ & 0.65 & $0.92(0.56-1.52)$ & 0.74 \\
\hline Smoking & 26 & $21(81)$ & $4(15)$ & $1(4)$ & $0.44(0.16-1.20)$ & 0.11 & $0.59(0.13-1.62)$ & 0.30 \\
\hline Previous IPD & 14 & $7(50)$ & $4(29)$ & $3(21)$ & $1.82(0.67-4.97)$ & 0.24 & $1.84(0.65-5.19)$ & 0.25 \\
\hline Tuberculosis & 8 & $5(63)$ & o (o) & $3(38)$ & $1.68(0.44-6.37)$ & 0.45 & $2.04(0.52-7.91)$ & 0.31 \\
\hline Other & 154 & $101(66)$ & 29 (19) & $24(16)$ & $1.05(0.74-1.48)$ & 0.79 & $1.05(0.73-1.51)$ & 0.78 \\
\hline
\end{tabular}

$\mathrm{Cl}$ : confidence interval; COPD: chronic obstructive pulmonary disease; HIV: human immunodeficiency virus; IPD: invasive pneumococcal disease; OLR: ordinal logistic regression; SD: standard deviation.

a Data missing for three patients. 
Disease outcome at hospital discharge by age and serotype for patients with invasive pneumococcal disease, Belgium, 2009-2011 $(n=1,214)$
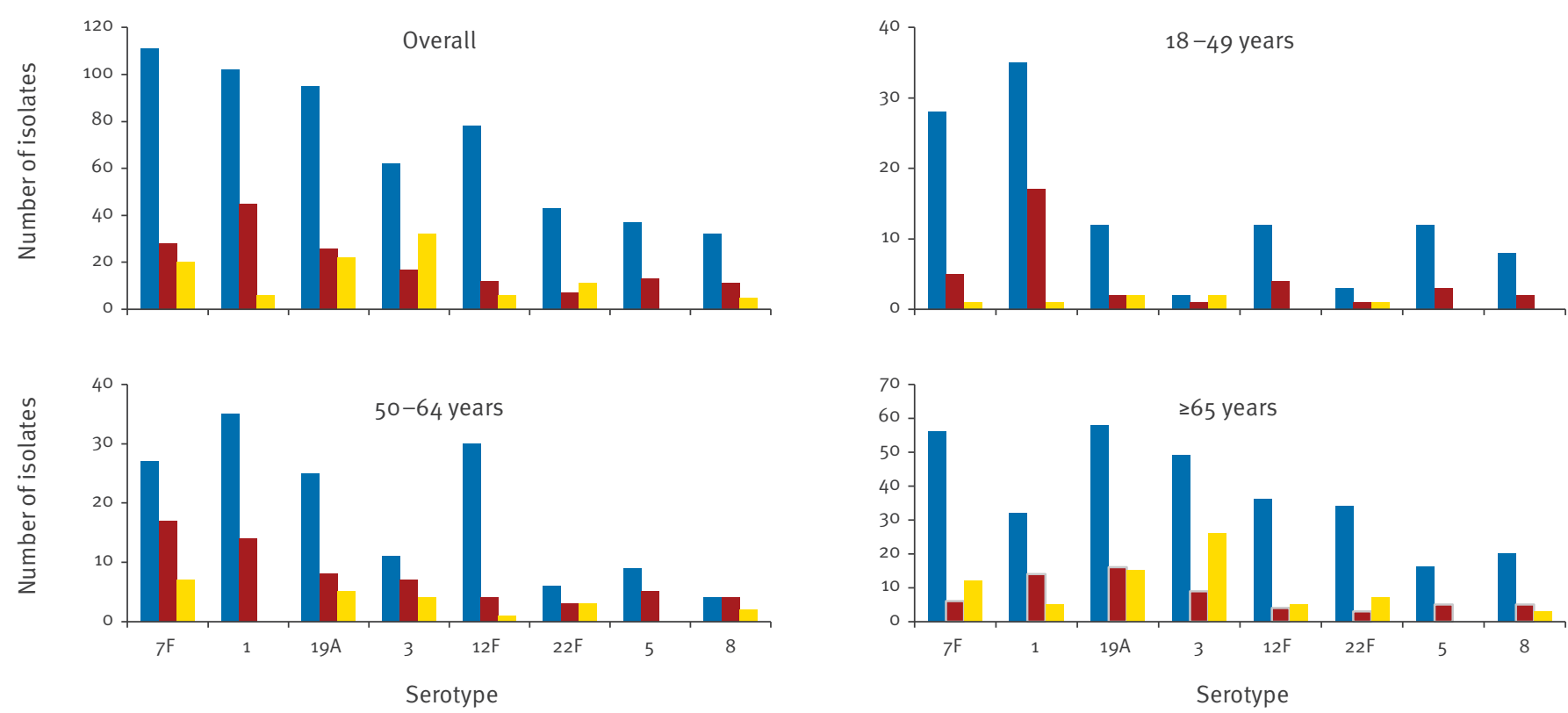

Cured

Discharged with persisting symptoms and signs

Death

Only the serotypes accounting for at least $4 \%$ of isolates overall are shown.

bacteraemic pneumonia (13\% (128/968)) and bacteraemia without focus $(17 \%(11 / 64))$, serotype 1 in those with empyema $(23 \%(18 / 80))$, and serotype $19 \mathrm{~A}$ in cases of meningitis $(11 \%(7 / 65))$.

Serotypes $12 \mathrm{~F}$ and $22 \mathrm{~F}$, not included in $\mathrm{PCV} 13$, accounted for $96(8 \%)$ and $61(5 \%)$ of the 1,214 IPD serotyped isolates, respectively. Serotypes $3(17 \%$ (32/188)), 19A (12\% (22/188)), and $7 \mathrm{~F}(11 \%(20 / 188))$ together accounted for nearly $40 \%$ of the 188 deaths with available serotype data. The highest case fatality rate was for serotype 6B (6 deaths for 11 cases; $55 \%$ ) but eight of the 11 patients were $\geq 65$ years of age. Among the six most frequent serotypes, the case fatality rates were $13 \%(20 / 159)$ for serotype $7 \mathrm{~F}, 4 \%(6 / 153)$ for serotype $1,15 \%(22 / 143)$ for serotype $19 \mathrm{~A}, 29 \%$ $(32 / 111)$ for serotype $3,6 \%(6 / 96)$ for serotype $12 \mathrm{~F}$, and $18 \%(11 / 61)$ for serotype $22 \mathrm{~F}$. None of the 50 patients with serotype 5 IPD died.

Most pneumococcal isolates were susceptible to the four antibiotics tested (Table 5). Among the 22 pneumococcal isolates non-susceptible to penicillin, 18 were of serotype 19A. Overall, among the 145 serotype $19 \mathrm{~A}$ isolates, 14 (10\%) were intermediately resistant $(\mathrm{MIC}=4 \mathrm{mg} / \mathrm{L})$ and four $(3 \%)$ resistant $(\mathrm{MIC} \geq 8 \mathrm{mg} / \mathrm{L})$ to penicillin, 95 (66\%) were resistant to tetracycline, and 85 (59\%) were resistant to erythromycin. Serotype 1 , represented by a total of 154 isolates, was also frequently resistant to tetracycline (76 isolates (49\%)) and erythromycin (74 isolates (48\%)). The 159 serotype
$7 \mathrm{~F}$ isolates were all susceptible to the four antibiotics tested.

Overall, infections caused by the seven serotypes included in $\mathrm{PCV}_{7}$ (serotypes 4, 6B, 9V, 14, 18C, 19F, and $23 \mathrm{~F}$ ) represented $7 \%(83 / 1,214)$ of IPD cases (Figure 2). Also, $54 \%(659 / 1,214)$ of cases were caused by the six additional serotypes included in $\mathrm{PCV}_{13}$ (serotypes $1,3,5,7 \mathrm{~F}, 19 \mathrm{~A}$, and $6 \mathrm{~A})$, while $25 \%(298 / 1,214)$ were caused by the additional serotypes included in PPV23, and $14 \%(174 / 1,214)$ were caused by serotypes not included in any of the pneumococcal vaccines. Among the patients $\geq 50$ years of age, the proportion of $\mathrm{PCV}_{7}$ serotypes decreased from $10 \%(33 / 325)$ in 2009 to $5 \%$ $(13 / 252)$ in $2011(p=0.028)$.

\section{Discussion}

In 2009, a prospective, active hospital-based study of morbidity and mortality of IPD in adults was started in Belgium. Data collected between 2009 and 2011 showed that mortality due to IPD was high, with up to $20 \%$ case fatality in adults $\geq 65$ years of age. Bacteraemic pneumonia was the most frequent clinical type of IPD. Of the 1,214 serotyped isolates, 742 (61\%) were included in $\mathrm{PCV}_{13}$, which thus included the most resistant and lethal isolates.

As in the current study, previous studies in the Netherlands, Spain and the United States (US) have shown that bacteraemic pneumonia predominates in adults [9-11]. Meningitis has been reported to be more frequent in young children [11,12]. In addition, we 
TABLE 5

Antibiotic susceptibility of pneumococcal isolates derived from patients with invasive pneumococcal disease, Belgium, 2009-2011 (n=1,214)

\begin{tabular}{|c|c|c|c|c|c|}
\hline \multirow{2}{*}{ Antibiotic } & \multicolumn{4}{|c|}{ Pneumococcal isolates, $\mathrm{n}(\%)$} & \multirow{2}{*}{ Resistant serotypes n (\%) } \\
\hline & Susceptible & Intermediate & Resistant & Unknown & \\
\hline Penicillin & $1,189(98)$ & $14(1)$ & $8(1)$ & $3(\ll 1)$ & $19 A: 4(3) ; 14: 1(4) ; 35: 1(7) ; 15 A: 1(8) ; 20: 1(20)$ \\
\hline Tetracycline & $945(78)$ & $2(\ll 1)$ & $264(22)$ & $3(\ll 1)$ & $\begin{array}{l}\text { 1: } 76(49) ; 19 \mathrm{~A}: 95(66) ; 12 \mathrm{~F}: 27(28) ; 3: 1(1) ; 22 \mathrm{~F}: 1(2) ; 5: 2(4) ; 8: \\
2(4) ; 6 \mathrm{~A}: 8(20) ; 14: 9(39) ; 33 \mathrm{~F}: 2(9) ; 11 \mathrm{~A}: 1(5) ; 24 \mathrm{~F}: 5(26) ; 35: 1 \\
(7) ; 15 \mathrm{~A}: 6(50) ; 6 \mathrm{~B}: 6(55) ; 38: 1(10) ; 19 \mathrm{~F}: 2(20) ; 15 \mathrm{~F}: 2(29) ; 9 \mathrm{~V}: 2 \\
(33) ; 23 \mathrm{~A}: 2(33) ; 9 \mathrm{~A}: 1(20) ; 20: 1(20) ; 15 \mathrm{~B}: 2(50) ; 15 \mathrm{C}: 1(25) ; 9: \\
2(67) ; 15: 1(50) ; 12 \mathrm{~B}: 2(50) ; 13: 1(100)\end{array}$ \\
\hline Ofloxacin & 1,206 (99) & o (o) & $3(\ll 1)$ & $5(\ll 1)$ & $1: 1(1) ; 14: 1(4) ; 29: 1(14)$ \\
\hline
\end{tabular}

Percentages in this column relate to the proportion of resistant isolates per total isolates of a given serotype. Serotypes with more than $50 \%$ of isolates resistant are shown in bold.

confirmed age as a risk factor for IPD and death due to IPD [11]. Chronic illness is another well-known risk factor for IPD [13-15]. In our study, more than threequarters of patients with IPD had at least one chronic underlying condition. This proportion was even higher for older adults. This confirms that patients with comorbidities have a higher risk of developing IPD. Patients with at least one comorbidity generally also had a higher risk of death in hospital due to IPD.

Universal mass vaccination of children aged $<2$ years with $\mathrm{PCV}_{7}$ has dramatically decreased the incidence of vaccine-type IPD in this population and, to a lesser extent, in older individuals through herd effect [16-18]. Nevertheless, even with successful mass vaccination, IPD remains a problem. The ongoing national surveillance will help determine how routine use of $\mathrm{PCV}_{13}$ in children further influences the epidemiology of IPD in adults. While PCV7-type IPD has decreased $[17,18]$, non-PCV7-type IPD has risen in many countries $[17,19$ 23]. Accordingly, we found $7 \%$ of IPD cases in adults caused by serotypes included in $\mathrm{PCV}_{7}$. Because four of the most frequent serotypes $(7 \mathrm{~F}, 1,19 \mathrm{~A}$, and 3$)$ in our study are included in the newly licensed PCV13, they should become less common as the use of PCV13 increases.

Our finding that serotypes $1,7 \mathrm{~F}$, and $19 \mathrm{~A}$ predominate corresponds with other reports $[6,19,23-25]$. Serotype 19 A was the third most prevalent serotype in adult IPD. Similarly, this serotype was previously reported as the second or third most prevalent serotype in IPD in children $<5$ years of age $[6,7]$. This is a concern because serotype $19 \mathrm{~A}$ is frequently multi-resistant to antibiotics. The incidence of serotype $19 \mathrm{~A}$ started to increase in children before the introduction of $\mathrm{PCV}_{7}$ and further increased after its introduction [6], suggesting that the rise is partly due to other factors, such as antibiotic consumption and secular trends. Serotypes $12 \mathrm{~F}$ and $22 \mathrm{~F}$ were the fifth and sixth most common serotype. Serotype $12 \mathrm{~F}$ has also become more common in young children since 2002-2003 [6]. Both serotypes are included in PPV23 but not in PCV13 and should be closely monitored in the future.

According to a review article, the reported case fatality rate for adult patients hospitalised with IPD has remained relatively stable at approximately $12 \%$ since the 1950 s [26]. We found a slightly higher rate of $16 \%$. The case fatality rate was low for serotypes 1 and 5 and high for serotypes 3 and $6 \mathrm{~B}$, as shown in previous studies in Denmark, the Netherlands and the US, $[16,27,28]$.

One limitation of our study is that older patients may have been over-represented because adults between 18 and 49 years of age were included only from the second year of study (2010), whereas adults $\geq 50$ years of age were included from the beginning of the study (2009). However, this should have little impact on the results because per year the majority $(51 \%)$ of patients were $\geq 65$ years of age, and the data were analysed per age group. Another possible bias of the results is that 543 of the $1,875(28 \%)$ eligible patients were not included in the analysis due to unavailable informed consent or late blood draw. Disease in these patients may have been more severe (patients in ICU) or less severe (patients who left the hospital before microbiological confirmation of IPD) than in the analysed population.

In conclusion, this study showed that, in Belgium, the mortality of IPD in adults is high, with a case fatality rate of $20 \%$ in patients $\geq 65$ years of age. The most common and virulent pneumococcal serotypes are included in $\mathrm{PCV}_{13}$, which adds support for the use of 


\section{FIGURE 2}

Proportion of invasive pneumococcal disease caused by serotypes included in pneumococcal vaccines, Belgium, 2009-2011 $(\mathrm{n}=1,214)$

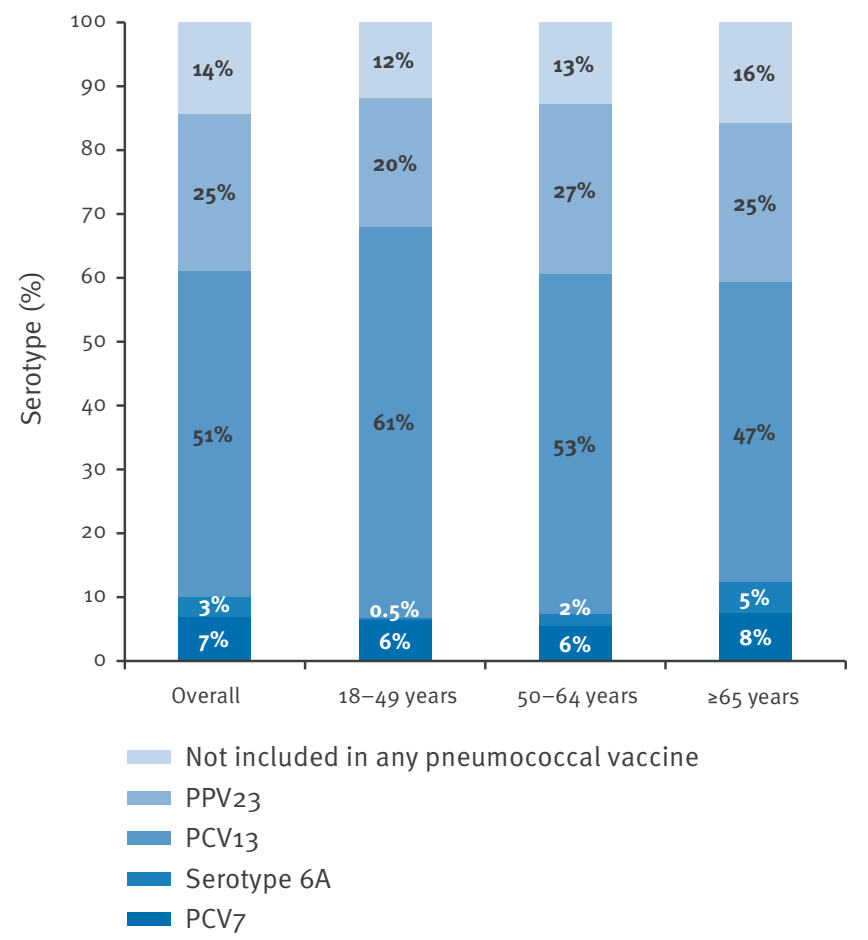

The 7-valent pneumococcal conjugate vaccine $\left(\mathrm{PCV}_{7}\right)$ included serotypes $4,6 \mathrm{~B}, 9 \mathrm{~V}, 14,18 \mathrm{C}, 19 \mathrm{~F}$, and $23 \mathrm{~F}$. The 13 -valent pneumococcal conjugate vaccine (PCV13) included additional serotypes 1, 3, 5, 6A, 7F, and 19A. Compared to PCV13, the 23-valent pneumococcal polysaccharide vaccine (PPV23) did not comprise serotype $6 \mathrm{~A}$, but included additional serotypes 2,8 , $9 \mathrm{~N}, 10 \mathrm{~A}, 11 \mathrm{~A}, 12 \mathrm{~F}, 15 \mathrm{~B}, 17 \mathrm{~F}, 20,22 \mathrm{~F}$, and $33 \mathrm{~F}$. Serotype $6 \mathrm{~A}$ was presented separately because it is included in PCV13 but not in PPV23. The total may be different from $100 \%$ due to rounding.

this vaccine in combination with the PPV23 in high-risk and older adults. In addition, these data are essential when assessing the impact of $\mathrm{PCV}_{13}$ vaccination in adults in the future.

\section{Acknowledgements}

Acknowledgement: The authors thank all the investigators who have contributed to the surveillance. The authors also thank Patricia Slachmuylders and Annick Mignon (Pfizer, Belgium) for study coordination, Pr. Adelin Albert and Nadia Dardenne (Université de Liège, Belgium) for statistical analysis, and Dr. Julie Harriague (4Clinics, France) for writing assistance.

Funding: This study was supported by Pfizer Belgium. Support for the writing assistance was also provided by Pfizer Belgium.

\section{Conflict of interest}

Jan Verhaegen has received grants from Pfizer. J. F. has received personal fees from Pfizer and is an advisor for the vaccine workgroup of the High Council of Public Health of the Belgian Federal Government and for the vaccine workgroup of the Flemish Government (unpaid activities). B. D. has received personal fees from Pfizer. K. V. H. has received consulting fees from Pfizer, research grants from Pfizer and GlaxoSmithKline Biologicals, and speaker fees from several vaccine manufacturers. Y. V. L. received personal and travel fees from Pfizer. P. V. D. acts as chief and principal investigator for vaccine trials conducted on behalf of the University of Antwerp, for which the University has obtained research grants from vaccine manufacturers. W. $P$. has received funds for advisory board membership from Pfizer, Bayer, AstraZeneca, GlaxoSmithKline Biologicals, Merck-Shering-Plough, and Astellas and research grants from Pfizer, Sanofi-Aventis, Bayer, and AstraZeneca. F. S. was an employee of Pfizer, which has a licensed pneumococcal conjugate vaccine, at the time of the study conduct. W. D. B.: none to declare. Writing assistance in preparation of this manuscript was provided by Dr. Julie Harriague (4 Clinics, Paris, France). This assistance included preparation of the first draft, incorporation of authors' contributions and revisions, and editing, all under the direction of the authors. At all stages, the authors had control over the content of this manuscript, for which they gave final approval and take full responsibility.

\section{Authors' contributions}

All authors participated actively since 2009 on the set-up of the study protocol, the follow-up of the study and the preparation of the manuscript.

\section{References}

1. Centers for Disease Control and Prevention. Update: pneumococcal polysaccharide vaccine usage--United States. MMWR Morb Mortal Wkly Rep. 1984;33(20):273-6, 281.

2. Conseil Supérieur de la Santé. Vaccination antipneumococcique de l'adulte (2013). [Pneumococca vaccination for adults]. Avis CSS $n^{\circ} 8817$. Brussels: Conseil Supérieur de la Santé; 2013. French. Available from: http:// www.health.belgium.be/eportal/Aboutus/relatedinstitutions/ SuperiorHealthCouncil/publications/factsheetsvaccination/ index.htm\#.UuorQD2E2Rc

3. Conseil Supérieur de la Santé. Recommandations pour la vaccination des enfants présentant un risque accru de maladie invasive à pneumocoques (MIP). [Vaccine recommendations for children at increased risk of invasive pneumococcal disease]. Avis CSS n 8757 . Brussels: Conseil Supérieur de la Santé; 2013. French. Available from: http://www.health.belgium.be/ eportal/Aboutus/relatedinstitutions/SuperiorHealthCouncil/ publications/factsheetsvaccination/index.htm\#.UuorQD2E2Rc

4. European Medicines Agency. Prevenar 13 (pneumococcal polysaccharide conjugate vaccine, 13-valent adsorbed) CMHP variation assessment report. London: European Medicines Agency; 2011. Available from: http://www.ema.europa.eu/ docs/en_GB/document_library/EPAR_-_Assessment_Report_Variation/human/001104/WC50011978

5. Institut Scientifique de Santé Publique (WIV-ISP). 2011 Annual report on pneumococcal surveillance. Brussels: WIV-ISP; 2011. Available from: https://www.wiv-isp.be/epidemio/epifr/plabfr/ plabanfr/11_030f_r.pdf

6. Hanquet G, Lernout T, Vergison A, Verhaegen J, Kissling E, Tuerlinckx D, et al. Impact of conjugate 7-valent vaccination in Belgium: Addressing methodological challenges. Vaccine. 2011;29(16):2856-64.

http://dx.doi.org/10.1016/j.vaccine.2011.02.016

7. Vergison A, Tuerlinckx D, Verhaegen J, Malfroot A. Epidemiologic features of invasive pneumococcal disease in Belgian children: passive surveillance is not enough. Pediatrics. 2006;118(3):e801-9. http://dx.doi.org/10.1542/peds.2005-3195

8. Clinical and Laboratory Standards Institute (CLSI). Performance Standards for Antimicrobial Susceptibility Testing: Twentieth Informational Supplement. Wayne, PA: CLSI; 2012. CSLI document M100-S22.

9. Ardanuy C, Marimon JM, Calatayud L, Gimenez M, Alonso M, Grau I, et al. Epidemiology of invasive pneumococcal disease in older people in Spain (2007-2009): implications for future 
vaccination strategies. PLoS One. 2012;7(8):e43619. http://dx.doi.org/10.1371/journal.pone.0043619

10. Bliss SJ, Larzalere-Hinton F, Lacapa R, Eagle KR, Frizzell F, Parkinson A, et al. Invasive pneumococcal disease among White Mountain Apache adults, 1991-2005. Arch Intern Med. 2008;168(7):749-55. http://dx.doi.org/10.1001/archinte.168.7.749

11. Jansen AG, Rodenburg GD, de Greeff SC, Hak E, Veenhoven $\mathrm{RH}$, Spanjaard L, et al. Invasive pneumococcal disease in the Netherlands: Syndromes, outcome and potential vaccine benefits. Vaccine. 2009;27(17):2394-401. http://dx.doi.org/10.1016/j.vaccine.2009.01.127

12. Institut Scientifique de Santé Publique (WIV-ISP). Surveillance des maladies infectieuses chez les enfants en Belgique. PediSurv - Rapport annuel 2010 [Surveillance of infectios diseases in children in Belgium - 2010 annual report]. Brussels: WIV-ISP; 2010. Available from: https://www.wiv-isp. be/PEDISURV/AnnualReports/2010/jaarverslag_2010_fr.pdf

13. Prevention of pneumococcal disease: recommendations of the Advisory Committee on Immunization Practices (ACIP). MMWR Recomm Rep. 1997;46(RR-8):1-24.

14. Kyaw MH, Rose CE Jr, Fry AM, Singleton JA, Moore Z, Zell $E R$, et al. The influence of chronic illnesses on the incidence of invasive pneumococcal disease in adults. J Infect Dis. 2005;192(3):377-86. http://dx.doi.org/10.1086/431521

15. van Hoek AJ, Andrews N, Waight PA, Stowe J, Gates P, George $R$, et al. The effect of underlying clinical conditions on the risk of developing invasive pneumococcal disease in England. J Infect. 2012;65(1):17-24. http://dx.doi.org/10.1016/j.jinf.2012.02.017

16. Lexau CA, Lynfield R, Danila R, Pilishvili T, Facklam R, Farley $M M$, et al. Changing epidemiology of invasive pneumococcal disease among older adults in the era of pediatric pneumococcal conjugate vaccine. JAMA. 2005;294(16):2043-51. http://dx.doi.org/10.1001/jama.294.16.2043

17. Pilishvili T, Lexau C, Farley MM, Hadler J, Harrison LH, Bennett $\mathrm{NM}$, et al. Sustained reductions in invasive pneumococcal disease in the era of conjugate vaccine. J Infect Dis. 2010;201(1):32-41. http://dx.doi.org/10.1086/648593

18. Whitney CG, Farley MM, Hadler J, Harrison LH, Bennett NM, Lynfield $R$, et al. Decline in invasive pneumococcal disease after the introduction of protein-polysaccharide conjugate vaccine. N Engl J Med. 2003;348(18):1737-46. http://dx.doi.org/10.1056/NEJMoa022823

19. Aguiar SI, Brito MJ, Goncalo-Marques J, Melo-Cristino J, Ramirez M. Serotypes $1,7 \mathrm{~F}$ and $19 \mathrm{~A}$ became the leading causes of pediatric invasive pneumococcal infections in Portugal after 7 years of heptavalent conjugate vaccine use. Vaccine. 2010;28(32):5167-73.

http://dx.doi.org/10.1016/j.vaccine.2010.06.008

20. Hicks LA, Harrison LH, Flannery B, Hadler JL, Schaffner W, Craig AS, et al. Incidence of pneumococcal disease due to non-pneumococcal conjugate vaccine $\left(\mathrm{PCV}_{7}\right)$ serotypes in the United States during the era of widespread $\mathrm{PCV}_{7}$ vaccination, 1998-2004. J Infect Dis. 2007;196(9):1346-54 http://dx.doi.org/10.1086/521626

21. Miller E, Andrews NJ, Waight PA, Slack MP, George RC. Herd immunity and serotype replacement 4 years after seven-valent pneumococcal conjugate vaccination in England and Wales: an observational cohort study. Lancet Infect Dis. 2011;11(10):7608 . http://dx.doi.org/10.1016/S1473-3099(11)70090-1

22. Mu-oz-Almagro C, Jordan I, Gene A, Latorre C, Garcia-Garcia JJ, Pallares R. Emergence of invasive pneumococcal disease caused by nonvaccine serotypes in the era of 7 -valent conjugate vaccine. Clin Infect Dis. 2008;46(2):174-82. http://dx.doi.org/10.1086/524660

23. Singleton RJ, Hennessy TW, Bulkow LR, Hammitt LL, Zulz T, Hurlburt DA, et al. Invasive pneumococcal disease caused by nonvaccine serotypes among alaska native children with high levels of 7 -valent pneumococcal conjugate vaccine coverage. JAMA. 2007;297(16):1784-92. http://dx.doi.org/10.1001/jama.297.16.1784

24. Grall N, Hurmic O, Al Nakib M, Longo M, Poyart C, Ploy MC, et al. Epidemiology of Streptococcus pneumoniae in France before introduction of the PCV-13 vaccine. Eur J Clin Microbiol Infect Dis. 2011;30(12):1511-9. http://dx.doi.org/10.1007/s10096-011-1251-9

25. Regev-Yochay G, Rahav G, Strahilevitz J, Bishara J, Katzir $M$, Chowers M, et al. A nationwide surveillance of invasive pneumococcal disease in adults in Israel before an expected effect of PCV7. Vaccine. 2013;31(19):2387-94. http://dx.doi.org/10.1016/j.vaccine.2013.02.059
26. Ludwig E, Bonanni P, Rohde G, Sayiner A, Torres A. The remaining challenges of pneumococcal disease in adults. Eur Respir Rev. 2012;21(123):57-65. http://dx.doi.org/10.1183/09059180.00008911

27. Jansen AG, Rodenburg GD, van der Ende A, van Alphen L, Veenhoven RH, Spanjaard L, et al. Invasive pneumococcal disease among adults: associations among serotypes, disease characteristics, and outcome. Clin Infect Dis. 2009;49(2):e239. http://dx.doi.org/10.1086/600045

28. Martens P, Worm SW, Lundgren B, Konradsen HB, Benfield $T$. Serotype-specific mortality from invasive Streptococcus pneumoniae disease revisited. BMC Infect Dis. 2004;4:21. http://dx.doi.org/10.1186/1471-2334-4-21 